\title{
El problema de los opuestos bajo la forma de la contradicción en la filosofía de Nietzsche
}

\author{
Vanessa Elsie Leyva ZegarRa
}

Pontificia Universidad Católica del Perú

Resumen: El artículo busca profundizar en el problema de la contradicción en la filosofía nietzscheana, tomando como principal referencia la interpretación de MüIler-Lauter. El objetivo principal es elucidar el camino que sigue Nietzsche hacia la postulación de la voluntad de poder como una lectura perspectivista de la realidad, que reemplace la tradicional noción de verdad metafísica. La argumentación se centra en refutar la equiparación del perspectivismo nietzscheano con la arbitrariedad de un relativismo burdo, mediante el examen de la relación entre voluntad de poder y voluntad de verdad.

Palabras clave: contradicción, relativismo, perspectivismo, voluntad de poder, voluntad de verdad

\begin{abstract}
This article delves into the problem of contradiction in Nietzschean philosophy, taking Müller-Lauter's interpretation as the main reference. Its main objective is to shed light on the path followed by Nietzsche towards the postulation of the will to power as a perspectivist reading of reality, which replaces the traditional notion of metaphysical truth. The argument focuses on refuting the equalization of Nietzschean perspectivism with the arbitrariness of a crude relativism, by examining the relationship between the will to power and the will to truth.
\end{abstract}

Keywords: contradiction, relativism, perspectivism, will to power, will to truth 


\section{§1. Introducción}

En Contra la comunicación, Mario Perniola realiza una ácida crítica de la sociedad contemporánea, a la que reprocha el refugiarse en un halo democrático para forzar la homologación de toda diferencia en un desesperante relativismo. Así, caracteriza psicológicamente a la sociedad de masas de la era globalizada como incapaz de percibir la oposición y acceder al conflicto, lo que resulta en el deseo de la completa anulación de toda identificación, de toda definición, de toda jerarquía (Perniola 2006, 21). Este comportamiento, que Perniola define como patológico, conllevaría, además, no solo a un optimismo irresponsable, sino, peor aún, a un absurdo sentimiento de superioridad: como si el no querer mantener una precisa identidad de pensamiento supusiera "la posesión de algún universal secreto" $(2006,22)$. No obstante, antes que ofrecer conclusiones apresuradas respecto de los antecedentes de este problema, a Perniola le interesa resaltar que la actitud irresponsable de la sociedad de la comunicación no debe, bajo ningún término, confundirse con la actitud filosófica. Esta última constituye, más bien, un esfuerzo por concebir la relación de oposición de manera cada vez más radical (Perniola 2006, 52). De hecho, señala Perniola, Aristóteles habría sido el primero en sistematizar los diferentes tipos de oposición ${ }^{1}$-entre los cuales la contradicción resulta el tipo fundamental para el desarrollo posterior de la lógica y la metafísica-, mientras que Hegel se encargaría de realizar el viraje decisivo para la comprensión sucesiva del problema, al sostener que la oposición, bajo la forma de la contradicción, no es solo una regla lógica de la razón, sino que forma parte de la propia dinámica de la realidad. Al parecer, según Perniola, Nietzsche sería, sin embargo, el primero que logra pensar la oposición de una forma que no se reduce a la inversión de lo idéntico $(2006,52-53)$, esto es, acepta el carácter contradictorio de la existencia sin sucumbir al dualismo metafísico $(2002,77)$, presente en mayor o menor medida en sus predecesores. En efecto, una oposición dualista, que se basa

1 De acuerdo con Perniola, Aristóteles distingue cuatro clases de oposición: (i) correlación o mutua referencia de opuestos, (ii) contrariedad, que involucra la existencia de un término medio entre los opuestos, fundamental para la ética aristotélica, (iii) posesión/privación, fundamental en la formulación de la ética platónica y (iv) contradicción, exclusión del término medio o principio de no contradicción, fundamental para el desarrollo de la lógica (Perniola 2006, 52). 
exclusivamente en lo que niega, tendría para Nietzsche un carácter "meramente reactivo, incapaz de afirmar la autonomía de la propia diferencia" (Perniola 2002, 77).

He considerado importante atender a esta acertada observación de Perniola respecto de Nietzsche, pues, lamentablemente, es un lugar común en diversas interpretaciones ligeras de su filosofía acusarla de arbitraria e irracional; y como tal, un posible fundamento o antecedente filosófico del caos comunicativo de la sociedad de masas, que, amparada en la proclamación contemporánea de la ausencia de toda normatividad de carácter metafísico -esto es, de una medida racional válida en todos los casos desde la cual establecer distinciones y jerarquías- busca reducirlo todo a un mero subjetivismo. No queremos afirmar con ello que el problema de los opuestos, bajo la forma de la contradicción, no sea conflictivo en la filosofía nietzscheana, que oscila entre la exigencia de establecer oposiciones (salud-enfermedad, fortaleza-debilidad) y la crítica a la formulación de lo que él considera falsos opuestos (ser-apariencia, verdad-mentira, sujeto-objeto, libertad-necesidad, guerra-paz). Como señala Müller-Lauter, el problema de las contradicciones en el pensamiento de Nietzsche encuentra una dificultad peculiar: "sus afirmaciones sobre la existencia de las contradicciones parecen ser ellas mismas contradictorias" (1999, 7; la traducción es nuestra). Así, mientras que en unos pasajes parece celebrar la riqueza de contradicciones de los hombres más altos, en otros, niega que puedan encontrarse, en absoluto, opuestos en la realidad.

Me interesa, pues, ahondar en el problema de la contradicción en la filosofía nietzscheana con el objeto de elucidar el camino que sigue Nietzsche hacia la postulación de un perspectivismo que reemplace la tradicional noción de verdad metafísica sin caer, por ello, en la arbitrariedad o la defensa burda de un desesperante relativismo. Tomaré como principal referencia en esta tarea la interpretación de Müller-Lauter, quien, a diferencia de otros autores, ha buscado otorgar significado y valor a las contradicciones, reales o aparentes, que puedan encontrarse en las principales ideas de Nietzsche, además de formular una lúcida crítica de toda lectura metafísica de su filosofía. 


\section{§2. Bases ontológicas del problema de los opuestos: contradicciones de la voluntad de poder}

Refirámonos nuevamente a la observación de Perniola: Nietzsche es el primer filósofo en proponer una forma de oposición que no se reduce a la inversión de lo idéntico. Esto es, una forma de oposición que no es absoluta e inamovible, una forma de oposición no metafísica. Para comprender esta observación es necesario caracterizar el nuevo tipo de oposición que Nietzsche propone: para él los opuestos "no son mutuamente excluyentes; pueden ser derivados uno del otro" (Müller-Lauter 1999, 11) en virtud del método genealógico, una de las principales herramientas que Nietzsche desarrolla y perfecciona para dar cuenta de tales virajes. Así, mediante el planteamiento de diversos escenarios históricos y psicológicos, Nietzsche logra reconstruir caminos plausibles entre opuestos y analizar sus posibles orígenes.

Veamos, entonces, siguiendo la pauta genealógica, cómo explica nuestro autor el origen de todo razonamiento lógico, aquel que identifica y opone:

¿De dónde ha surgido la lógica en la cabeza humana? Ciertamente desde lo ilógico, cuyo reino tuvo que haber sido originariamente enorme (...) Quien, por ejemplo, en relación con la alimentación o con los animales hostiles, no sabía encontrar lo "igual" con suficiente frecuencia, quien, subsumía, por lo tanto, con demasiada lentitud, quien era demasiado precavido en la subsunción, tenía simplemente menos probabilidades de sobrevivir que quien, entre todo lo similar, daba de inmediato con lo igual. Pero la tendencia predominante de tratar a lo similar como igual, una tendencia ilógica -pues en sí no hay nada idéntico- ha creado todos los fundamentos de la lógica. De la misma manera, para que surgiera el concepto de sustancia, que es imprescindible para la lógica, aunque en el sentido más estricto no le corresponde nada real, durante largo tiempo no tenía que verse, no tenía que percibirse lo variable en las cosas; los seres que no veían con exactitud tenían ventaja respecto de aquellos que veían todo 'en su fluir"' (Nietzsche 2014a, 796-797).

De la cita presentada podemos extraer reflexiones interesantes. Primero, la observación de que la fuente de todo razonamiento lógico nace de su opuesto: lo ilógico, a saber, la tendencia a asumir como igual lo que es meramente similar y fijar lo que siempre es variable. Segundo, la hipótesis, 
evolutivamente plausible, de que toda tendencia escéptica, toda precaución al inferir o establecer relaciones de identidad o a comparar en términos de grados y no de manera absoluta, representara un gran peligro para la vida del hombre primitivo (Müller-Lauter 1999, 8). Tercero, el planteamiento de que las ideas de sustancia y fijación nacieran de seres con una mirada demasiado corta para advertir la continua mutabilidad de las cosas, inmersas en un flujo perpetuo, planteamiento de influencia evidentemente heracliteana ${ }^{2}$. Seres que, nuevamente, obtenían una ventaja competitiva de su incapacidad para observar con mayor detenimiento y atención la realidad. Todo ello refuerza la tesis de que toda lógica nace, efectivamente, de un proceder ilógico, aunque ventajoso para la supervivencia. Por último, si bien en la cita señalada Nietzsche no hace referencia explícita a los opuestos, tiene sentido plantear un origen similar para la oposición de lo que es solo diferente, y advertir cómo esta exige, a su vez, el equívoco de suponer que aquello que se opone mantiene una identidad fija en el tiempo: no puede haber oposición absoluta, metafísica, sin identidad, sin fijación.

Es importante resaltar que Nietzsche no sostiene que este proceder "lógico" sea despreciable, todo lo contrario, se trata de un recurso simplificador vital: el hombre no puede vivir sin sus ficciones (Nietzsche 2012, 31). El problema surge cuando, en virtud de tal proceder, se postula una verdad metafísica, absoluta, que niega o desconoce que toda fijación es solo una ficción que responde a determinado interés, como el de la supervivencia. De ello se sigue que la expresión lógica esencial para el problema de los opuestos, el principio de no contradicción -según el cual una y la misma cosa no puede tener predicados opuestos al mismo tiempo-, no tenga necesidad objetiva para Nietzsche. En efecto, en diversos pasajes él defiende la contradicción y la realidad de los opuestos como inherentes al mundo,

2 En La filosofía en la época trágica de los griegos, Nietzsche sostiene: "Heráclito desiste de separar un mundo físico de otro metafísico, un reino de cualidades determinadas de un reino de indeterminación indefinible. Y he aquí que una vez dado ese primer paso no pudo ya abstenerse de una mayor intrepidez en la negación: negó el ser en general. En efecto este mundo único que él conservaba -este mundo protegido por leyes eternas y no escritas, animado por el flujo y el reflujo, inmerso en la férrea cadencia del ritmo- no revela nunca una permanencia, algo indestructible, un baluarte en la corriente. Exclama Heráclito: "No veo más que devenir. ¡No os dejéis engañar! Depende de la cortedad de vuestra vista y no de la esencia de las cosas que creáis ver tierra firme en medio del mar del devenir y el perecer" (Nietzsche 2003, 57-58). 
en contra de los postulados de la lógica que las oscurecen reemplazándolas por contradicciones meramente aparentes (Müller-Lauter 1999, 10). Ahora bien, si aceptamos que la realidad debe concebirse como un continuum de cambios incesantes, en el que nada permanece ¿tiene sentido hablar, entonces, de contradicción entre opuestos? Para poder responder esta pregunta es necesario mostrar las consecuencias que se derivan de la negación de lo constante en favor del proceso puro, que es, a fin de cuentas, lo que Nietzsche se propone pensar (Müller-Lauter 1999, 11).

Analicemos, pues, la que, probablemente, es la consecuencia más directa y perturbadora de la propuesta nietzscheana: la falsedad de la unidad e identidad intrínseca que predica sobre sí mismo el hombre, aquel que se arroga la facultad de establecer identidades y oposiciones. Para Nietzsche, tanto la noción de sujeto como la de individuo son inapropiadas, pues, en su significado tradicional, ambas implican que los diversos estados similares que se suceden en nosotros son el efecto de un sustrato de tipo aristotélico que subyace a cambios meramente superficiales. El yo "es nuestro más antiguo artículo de fe" (Nietzsche 2014b, 425). Müller-Lauter ofrece una interpretación esclarecedora del problema:

El cambio es omnipresente: no hay nada permanente a la base de lo cual sucede, de manera que el individuo se disuelve en una multiplicidad de individuos que se suceden en momentos infinitesimalmente pequeños (...) ¿qué es, no obstante, lo que sostiene esta multiplicidad junta en un contexto que permite hablar de un proceso? ¿Qué hace posible que hablemos en absoluto de una secuencia de eventos? La secuencia es constituida por el antagonismo de una multiplicidad de fuerzas (...) entre esta multiplicidad de fuerzas, una fuerza especifica siempre toma el mando (...) por lo tanto, se trata de una relación de conflicto permanente entre las fuerzas. Este conflicto es la condición para todos los eventos y no puede detenerse (1999, 12-13; la traducción es nuestra).

Solo como producto del juego de fuerzas es posible concebir el alineamiento temporal de estas en una unidad ficcional que se impone al resto. Las fuerzas específicas no tienen, pues, existencia propia, no son capaces de desplegarse de forma autosuficiente (a manera de múltiples esencias o mónadas irreductibles), sino que existen únicamente en la referencialidad conflictiva y cambiante de unas con otras, en un todo en flujo permanente (Müller-Lauter 1999, 15). A este "todo" lo denominará Nietzsche: voluntad 
de poder. La voluntad de poder es una especie de cualidad común a la multitud de conciencias y voluntades, de particularizaciones que difieren en términos de poder $y$, por ende, solo existe como esta multiplicidad (Müller-Lauter 1999, 19). Para Nietzsche, nada tiene una duración ilimitada, intemporal, cada "quantum de poder" está siempre en flujo, cambia constantemente, ya sea incrementando su poder, esto es, integrando nuevos cuanta, o disminuyéndolo, es decir, desintegrándose (Müller-Lauter $1999,21)$. No existe un cuanta indivisible de poder que podamos alcanzar porque su naturaleza es relacional y fluida (Müller-Lauter 1999, 132). En ambos casos, no obstante, es la contradicción entre los cuanta el fundamento de toda agregación y desagregación: la oposición, bajo la forma de la contradicción, es fundamental e intrínseca a la voluntad de poder. Su unidad y, por ende, la individualidad, solo puede pensarse en tanto relación recíproca de dependencia de todas las fuerzas en un sistema en continua transformación, y no como algo distinto al sistema bajo la forma de un principio fundante que lo subyace, antecede o trasciende y que se externaliza como religión o arte o se realiza en el ser humano (Müller-Lauter 1999, 134). "Lo único que está suficientemente demostrado es que el mundo no tiende a un estado duradero"3 (Nietzsche 2014b, 428). Por lo expuesto anteriormente, la voluntad de poder no podría encajar en la noción de ser, anclado en la identidad metafísica, absoluta, y debe comprenderse, más bien, como pathos (Müller-Lauter 1999, 22).

Finalmente, es necesario señalar que la voluntad de poder es siempre voluntad "de algo", que no se limita en absoluto a la voluntad de supervivencia o de vida -no en vano, podemos encontrar diversos pasajes en los que Nietzsche invita a la "muerte libre". Esta voluntad, además, no procede teleológicamente en dirección a ese "algo", en el sentido aristotélico o hegeliano de una disposición o un sentido preestablecido, tampoco como una voluntad ciega e incapaz de intelecto, a la manera de Schopenhauer, pues esto también es teleología (Müller-Lauter 1999, 15). Tampoco tiene por qué limitarse al ser humano, que constituye una unidad ficcional entre otras. No hay, pues, un último poseedor de la voluntad.

3 Esta afirmación ontológica de la voluntad de poder como realidad de la multiplicidad en flujo permanente se encuentra también enraizada en la filosofía heracliteana, probablemente la única que Nietzsche considera digna antecesora de su pensamiento. 


\section{$\S 3$. Voluntad de verdad y perspectivismo}

En el apartado anterior hemos profundizado en el carácter ontológico de la voluntad de poder como eje articulador de una realidad caracterizada por el flujo perpetuo. El problema que nos convoca requiere, sin embargo, que nos centremos en una variante de dicha voluntad: la voluntad de verdad.

Nietzsche describe al siglo XIX como una época que se encuentra "enferma de su multiplicidad", una época donde prima la desintegración de voluntades, no solo entre "individuos" sino al interior de cada "individuo" (Müller-Lauter 1999, 24). El hombre del siglo XIX, heredero de la llustración, caracterizado por una mayor apertura cultural y conciencia histórica de la evolución de los sistemas de valores, atraviesa una crisis de identidad posiblemente similar a la que caracteriza a las sociedades contemporáneas: su aceptación dócil de la heterogeneidad en las valoraciones respecto de la vida, lo habían vuelto incapaz de establecer estándares seguros que le permitan afirmar algo y condenar lo otro (Müller-Lauter 1999, 24). Dadas estas circunstancias, Nietzsche se encontró con una paradoja problemática: precisamente, el sentido histórico y científico que se presentaba para él como clave de la salud del hombre, en tanto le permitía entenderse como el resultado histórico de conflictos sucesivos con creencias y prejuicios impuestos por la tradición, era responsable de la destrucción de la convicción de su poder y de la confianza en sí mismo. En sus Consideraciones intempestivas Nietzsche reflexiona:

La consideración científica ve en todas partes algo que deviene, algo que es histórico, pero no algo que es, algo eterno, vive por consiguiente tanto en una contradicción intrínseca con los poderes eternizantes del arte y la religión como odia el olvido, la muerte del saber, busca así superar todo aquello que limita el horizonte, mientras arroja al hombre al infinito (...) ¿Puede el hombre vivir así? (...) la vida misma se destruye debilitándose y desmoralizándose cuando el terremoto conceptual provocado por la ciencia quita al hombre toda seguridad y tranquilidad, toda su creencia en lo que persiste y es imperecedero, ¿debe dominar la vida sobre el conocimiento o el conocimiento sobre la vida? ¿Cuál de los dos poderes es el superior y decisivo? Nadie ha de dudar: la vida es el poder máximo dominante, porque un conocimiento que destruye la vida acabaría consigo mismo. El conocimiento presupone la vida, tiene su interés también en la conservación de la vida. Así, pues, la ciencia necesita una dirección 
y vigilancia superiores: una doctrina de la salud de la vida ha de colocarse justo al lado de la ciencia" $(1999,136)$.

La cita corresponde a lo que se solía calificar como la fase "positivista" o "científica" del pensamiento de Nietzsche, pues parece una interrupción o inversión de sus motivos iniciales, según los cuales, el arte debía prevalecer y la ciencia debía ser cuestionada desde la óptica del arte, si bien la cuestión de la vida se mantiene como hilo conductor entre ambas fases. Ahora bien, la "doctrina de la salud" a la que debe someterse la ciencia, aunque sea consciente de la imposibilidad de toda fijación, parece no poder renunciar al ser, lo imperecedero, "lo supra-histórico", como garante de sentido. Pareciera que Nietzsche considera, aún, que el hombre necesita aferrarse a algo fijo, a algo que está más allá de él, para poder afirmarse a sí mismo en el proceso de devenir histórico, y evitar un estado de "parálisis mental", que lo lleve a la inactividad, producto del debilitamiento de sus fuerzas.

A medida que Nietzsche avanza en su crítica de la metafísica, sin embargo, el antídoto de lo "supra-histórico" es abandonado, en tanto ficción alienante y calumniadora de la vida: la historia, en tanto continuum del devenir, no debe entenderse como una conexión de causas y efectos, orientadas según un sentido teleológico o de progreso; la historia no tiene un objetivo impuesto desde afuera ni uno inmanente. Nietzsche no quiere cerrar ya los ojos al conocimiento científico, más aún, buscará llevarlo a sus últimas consecuencias (Danto 1980, 70). Así, Nietzsche se propone indagar por el origen y el significado mismo de toda ciencia y llega a la conclusión de que esta se encuentra enraizada en el entendimiento moral del mundo, que tiene su origen en la voluntad de poder del débil, del enfermo, el cual "creó una confusión del dogmatismo ideal con el conocimiento en general" (Nietzsche 2014b, 396):

El proyecto consistía en engañarse de una manera útil (...). Pero lastimosamente se puso en juego una categoría moral: ninguna criatura desea engañarse, ninguna criatura, mejor dicho, debe engañarse; $y$, por consiguiente, no hay más que una voluntad de lo verdadero. ¿Qué es la verdad? La antinomia brindaba este esquema: el mundo-verdad, cuyo camino se busca, no puede vivir en contradicción consigo mismo, no puede cambiar, devenir, puesto que no tiene principio ni fin (...) Y he aquí que el mundo adquiere un tono falso, a causa justamente de las 
cualidades que constituyen su realidad: el cambio, el devenir, la multiplicidad, los contrastes y las contradicciones, la guerra" (Nietzsche 2014b, 396).

¿Cómo logró el débil imponer su interpretación moral del mundo? Nietzsche advierte que solo contra la voluntad debilitada del fuerte es que la contra-voluntad originalmente reprimida del débil pudo haberse desplegado y para ello, fue necesario activar un medio que solo este tuviese disponible, o que lo tuviese en mayor grado que el fuerte: inteligencia, ingenio, habilidad, astucia (Nietzsche 2006, 63). Un instrumento que empleó con mucho éxito en contra de los instintos inconscientes o la imprudencia de los fuertes. Hasta ese momento el fuerte había sido creador de valores. Pero, al tomar el poder, el débil, movido por el resentimiento, se propone configurar nuevos valores, opuestos a los anteriores: “La rebelión de los esclavos en la moral comienza cuando el resentimiento mismo se vuelve creador y engendra valores" (Nietzsche 2006, 59). Esta nueva moralidad se caracteriza, además, por una pretensión eternizante, que busca ocultar, a toda costa, su origen y dependencia del devenir. De esta inversión, de esta voluntad de engaño nace, para Nietzsche, la voluntad de verdad (Müller-Lauter 1999, 60). La historia del mundo-verdad se revela, entonces, paradójicamente, como la "historia de un error": surge con el idealismo platónico (mundo verdadero asequible al sabio), deviene en cristianismo (mundo verdadero inasequible, pero prometido al penitente), luego, en racionalismo kantiano (mundo verdadero inasequible, imprometible, "pero ya en cuanto pensado, un consuelo, una obligación, un imperativo") y desemboca en el "Canto de gallo del positivismo", la figura del león, del "último hombre" dispuesto a luchar contra "el último dios" de la moral objetiva (Nietzsche 2013, 71-72).

De acuerdo con lo expuesto anteriormente, la etapa científica correspondería, para Nietzsche, con la del nihilismo (etapa del "filósofo del martillo") que ha sido capaz de reconocer en la voluntad de verdad un problema fundamentalmente moral y no un problema lógico o epistemológico, y rechazar, por ello, todos los valores metafísicos como lecturas falsificadoras y debilitadoras. “¿Cuándo dejarán de oscurecernos todas esas sombras de Dios?" (Nietzsche 2014a, 795). La "muerte del último dios" es el símbolo 
del abandono de todos los trasmundos4: "Llegará el día en que los más solemnes conceptos, causantes de tanta lucha y sufrimiento, los conceptos de Dios y de pecado no nos parezcan más relevantes de lo que el juguete de un niño y el dolor de un niño le parecen a un adulto -y quizá el adulto necesitara entonces un nuevo juguete y un nuevo dolor -aun niños, jeternamente niños!" (Nietzsche 2012, 104). El nihilismo es, no obstante, solo el primer paso, un periodo intermedio, en la liberación del hombre respecto de la mentira de la verdad moral, "antes que la fuerza sea suficiente para volver los valores, para divinizar y aprobar el mundo del devenir y de la apariencia como el único mundo" (Nietzsche 2014b, 399). Nietzsche dirige, pues, sus esperanzas hacia un contra-movimiento, hacia una nueva relación antitética, que se constituya como el opuesto del nihilismo, pero, -y esto es crucial- que lo presuponga lógica y psicológicamente5: "Muertos están todos los dioses: ahora queremos que viva el superhombre" (Nietzsche $2009,146)$. A diferencia del nihilista, que "piensa que el mundo tal como es no tiene razón de ser y que el mundo tal como debería de ser no existe" (Nietzsche 2014b, 400), es decir, que cree que una vez que se desmorona el mundo-verdad solo queda un mundo falso en el que existir (obrar, sufrir, querer, sentir) carece de sentido, el superhombre percibe que, una vez que se abandonan los trasmundos, se suprime la dualidad entre verdad y apariencia, y solo queda el mundo real.

Ahora bien, ¿la negación de la verdad absoluta-metafísica implica para Nietzsche que toda voluntad de verdad $y$, por ende, todo criterio de verdad deba ser abandonado? Sostenemos que, a diferencia de lo que sugieren algunos estudiosos, Nietzsche no desestima en absoluto la voluntad de

4 Incidamos en que no se trata, para Nietzsche, de afirmar que dios nunca existió. Tanto los dioses paganos como el cristiano han sido potencias reales mediante las cuales, y en función de las cuales, el hombre ha moldeado, y continúa moldeando en muchos casos, su existencia práctica. El primer paso de la inversión no puede suprimir esta realidad y desconocer su acción en el mundo, sino que debe superarla en tanto se ha vuelto insostenible y, con ella, toda la moral construida sobre la base de dicha fe.

5 Como podemos notar, las figuras antitéticas que identifica Nietzsche en su reconstrucción de la "Historia de un error" no son absolutas, se van transformando en el tiempo: la oposición fuerte-débil, se transforma en la oposición débil-nihilista y esta, a su vez, en la oposición nihilista-superhombre. Ello no debe confundirse, no obstante, con una posible teleología de carácter metafísico, sino que se trataría más bien de un telos en tanto posibilidad real, material, de su despliegue práctico en el futuro. 
verdad, más aún, la reconoce como imprescindible para la existencia humana, pero demanda que el problema del valor de la verdad no se separe de la voluntad de verdad (Nehamas 2002, 65). La verdad es el valor sin el cual no podemos vivir (Nietzsche 2014b, 343), pero el "problema de los valores siempre es más importante que el de la certeza; este último se convierte en algo que importa, después de plantearse el problema de los valores" (Nietzsche 2014b, 406). Tenemos aquí un importante argumento en contra del subjetivismo o relativismo (entendido de forma negativa) que se le imputa a Nietzsche, pues él sí admite el valor decisivo de la voluntad de verdad para la vida y, por ende, la necesidad de un criterio de verdad, solo que este no puede ser ya el principio de no contradicción de la lógica, útil solo si falsificamos la realidad fijándola en identidades absolutas. Tanto el que fija como el objeto de la fijación cambian continuamente (Müller-Lauter 1999, 147); en consecuencia, debe surgir una nueva noción de verdad que se diferencie sustancialmente de su antigua acepción, de manera que pueda corresponder con la realidad del devenir. No tenemos derecho a asumir ninguna cognición como absoluta, el carácter perspectivo es parte de la existencia, no solo de todo conocimiento, sino de toda acción, de todo desarrollo, de todo evento: "No hay hechos, solo interpretaciones" (Nietzsche 2014b, 474). El mundo no tiene ningún rasgo independiente de la interpretación que pueda hacerse de él (Nehamas 2002,65) y por ende, esta no debe ser entendida bajo su connotación moral como falsificación, engaño o error, sino como perspectivismo en el sentido de que el conocimiento para Nietzsche implica una relación con el mundo que no puede estar exenta de valores, objetivos e intereses específicos (Nehamas $2002,71)$. Tampoco debe equipararse el perspectivismo al fenomenalismo kantiano. No es la apariencia ni el objeto para mí del conocimiento, en lugar del mundo en sí mismo, sino más bien "el mundo mismo desde esa perspectiva" (Nehamas 2002, 72), a saber, que no puede haber una sola perspectiva, pues el carácter relacional de la "voluntad de poder" implica que hay varios elementos no fijos en juego. Ahora bien, si para Nietzsche todo conocimiento es siempre interpretación y toda interpretación tiene siempre un carácter perspectivo, ¿no se revierte ello contra las tesis de su propia filosofía? ¿En qué sentido es posible hablar siquiera de verdad? Más aún ¿el propio hecho de que la interpretación de Nietzsche se reclame 
como una interpretación más coherente del mundo respecto de filosofías anteriores no resulta contradictorio?

Para responder a estas interrogantes es necesario precisar cuál es el nuevo criterio de verdad que propone Nietzsche, como reemplazo al criterio metafísico y moral de la lógica. En el parágrafo 528 de La voluntad de poder, afirma: "El criterio de la verdad está en razón directa del aumento del sentimiento de fuerza" (Nietzsche 2014b, 366). Detengámonos en esta afirmación, pues, como observa Müller-Lauter, si profundizamos en el significado del poder y la fuerza de determinada voluntad, estas no podrían valorarse únicamente por su éxito previo en la historia (Müller-Lauter 1999, 153-154). Como señalamos líneas arriba, para Nietzsche el periodo de dominio de la concepción moral del mundo no es una expresión de fuerza, sino de debilidad. Sirviéndose, entre otros instrumentos, de la "interiorización del hombre" mediante la creación de un sentimiento de culpa inexpiable, el débil logró imponer su interpretación del mundo (Nietzsche 2006, 99); pero, al tratarse de una voluntad de poder que no se reconoce como tal, un dominio que se sostiene únicamente en el debilitamiento del más fuerte no podría haberse liberado como verdadera voluntad de poder. Nietzsche no niega, reincidamos en ello, que el dominio del débil sea una expresión de su voluntad de poder, pero al ser una interpretación que persigue una realidad definitiva para preservarla, al ser una interpretación que condena el cambio y el devenir, entonces, no puede ser una interpretación que sirva al incremento del sentimiento de fuerza o de poder $y$, en este sentido, es menos verdadera que una que sí comprende el perspectivismo de toda interpretación.

¿Por qué hace derivar precisamente el sufrimiento del cambio, de la ilusión, de la contradicción? ¿Por qué no hace derivar de ellos su felicidad? (...) ¿Cuál es el hombre que razona de esta manera? Una especie improductiva y doliente, una especie fatigada de la vida. Si imaginamos la especie de hombre contraria, nos encontraríamos con que la misma no tendría necesidad de la creencia en el ser, o más claro todavía, que despreciaría al ser como algo muerto, enojoso, indiferente. La idea de que el mundo que debería ser existe verdaderamente, es una creencia de los improductivos, que no anhelan crear un mundo tal y como debería ser. Consideran que existe ya, buscan los medios para llegar a él (Nietzsche 2014b, 400). 
Es por ello que Nietzsche considera las contradicciones que llevarían a la abolición de su propio criterio de verdad, como inaceptables. El ejercicio del poder no puede ser considerado por nuestro intelecto a la vez posible e imposible, pues este se encuentra, finalmente, al servicio del ejercicio del poder, "el auto-entendimiento de la interpretación como interpretación no debe ser dirigida contra la voluntad de poder, sino que, precisamente, puede y debe liberarla" (Müller-Lauter 1999, 157; la traducción es nuestra). De modo que, al rechazar la contradicción, en este caso, Nietzsche no se sirve del principio lógico formal como criterio de verdad, sino de la "imposibilidad para el mismo órgano de la voluntad de poder desempeñar funciones que se destruyan mutuamente" (Müller-Lauter 1999, 158; la traducción es nuestra).

Respecto de la contradicción que supondría que Nietzsche defienda su teoría de la voluntad de poder como más coherente o verdadera que otras teorías para interpretar el mundo, es preciso señalar que Nietzsche sí repara en dicha consecuencia, y afirma, de hecho, la necesidad de que, todas las interpretaciones, incluida la suya, en tanto expresiones de la voluntad de poder, son perspectivas (Müller-Lauter 1999, 148). Pero este perspectivismo no puede, naturalmente, equipararse a un relativismo absoluto, ya que Nietzsche postula un criterio de verdad para juzgar el valor de diferentes perspectivas: aquellas que se revelan como voluntad de poder sin disfraces, aquellas que abrazan el carácter cambiante, perspectivo y contradictorio de la realidad como garante de "la buena conciencia" que les permite perseguir e implementar incondicionalmente sus ideales son más verdaderas, más nobles y mejores que aquellas que surgen del resentimiento de una debilidad que busca preservarse, refugiándose en trasmundos. Lo que sí se ha abandonado es la posibilidad de alcanzar una verdad absoluta, el carácter fluido de la realidad no lo permite. "Las 'interpretaciones del mundo' subliman de diversa manera los impulsos; pero 'lo que es común' a todas estas interpretaciones es que 'son síntoma de un impulso dominante', es decir que 'los impulsos dominantes' tienen pretensiones, 'quieren ser considerados (...) como las instancias valorativas más altas en general, más aún como poderes creativos y gobernantes"' (Conill 2007, 161). 


\section{§4. La transvaloración de todos los valores como tarea futura}

Puesto en entredicho el principio de no contradicción, a Nietzsche no le cabe ninguna duda de que la filosofía se confronta con una "transvaloración" de todos los valores, algo que, como mencionamos líneas arriba, no implica retomar las valoraciones que precedieron a la valoración moral del mundo, sino que se trata de valorar desde una vitalidad consciente, pensante e histórica. Solo una vez que se asume conscientemente la "muerte de Dios", es posible comprender que los valores de la verdad moral son en realidad producto de un error profundo en tanto, a pesar de haber surgido del hombre como un impulso de auto-trascendencia, se le han presentado a lo largo de la historia como valores objetivos, incuestionables y universales, que debe obedecer y a los que debe someterse. Vivir humanamente significa valorar, pero los valores no son ideas fijas, sino formas de vida y síntomas de una determinada configuración de la voluntad de poder, ni eterna ni inmutable: "no estamos ante una 'verdad' en lucha con la vida, sino ante una especie de vida en lucha con otra vida. ¡Esta quiere ser la especie más destacada! Aquí es preciso introducir la demostración de la necesidad de una jerarquía; debe demostrarse que el problema esencial consiste en conferir una jerarquía a las varias especies de vida" (Nietzsche 2014b, 407). Ahora bien, una vez que reconocemos que el mundo no tiene significado por sí mismo ni a la base de sí mismo, el sinsentido que caracteriza al nihilismo no tiene para Nietzsche la última palabra, sino que toca al hombre otorgarle significados: "Conducid de nuevo a la tierra, como hago yo, a la virtud que se ha perdido volando - sí, conducidla de nuevo al cuerpo y a la vida: ¡para que dé a la tierra su sentido, un sentido humano!" (Nietzsche 2009, 143). La transvaloración supone, en consecuencia, tanto el reconocimiento del origen de los valores morales tradicionales (momento genealógico negativo), como su examen y de-construcción, para la futura construcción de nuevos valores (momento positivo activo, propiamente transvalorador), lo que no supone, empero, una apuesta por un relativismo absoluto, ya que, repitámoslo, Nietzsche propone criterios de verdad para la configuración de nuevas jerarquías de valores, según los cuales, la voluntad de poder dominante no debe ni puede, bajo ninguna circunstancia, solidificarse y limitarse a una sola perspectiva. Así, para evitar caer nuevamente en el error de la metafísica, la nueva verdad debe alcanzar 
una doble actitud: creer en sí misma, pero, simultáneamente, prepararse para renunciar a esa creencia (Müller-Lauter 1999, 70). ¿A quién compete esta tarea? Nietzsche propone que el filósofo como "médico de la cultura" es el que se encuentra capacitado para identificar, sirviéndose de diversos recursos metodológicos ("psicológicos", "históricos", "científicos"), cuándo en la voluntad de poder predomina la disgregación/enfermedad o la conjunción/salud. Y, si un particular sistema de pensamiento reclama para sí la premisa de ser el único que puede establecer valores, con prescindencia de todos las demás, y cree que su perspectiva está exenta de error, debe rechazarla, pues, todo intento de descubrir, de una vez y para siempre la naturaleza real del mundo mediante la estipulación de valores absolutos, es un deseo de trasmundo.

La experiencia nos ha demostrado que los diversos sistemas de valores éticos, estéticos, e incluso veritativos no son inmutables, varían en diversos sentidos, culturales e históricos. La consciencia de la mutabilidad y contingencia de todo juicio nos ha permitido entender el carácter perspectivo de toda valoración de lo que es bueno, bello, justo o verdadero. Pero, como señala Rovelli, aunque sana e importante esta conciencia del otro, no debe ser caricaturizada como una relativización total de los valores que nos lleve a la conclusión de que todas las opiniones son igualmente verdaderas, "reconocer que podemos estar equivocados no significa que las nociones de error y razón no tienen sentido. (...) Es cierto que no hay valores de verdad absolutos, ahistóricos y aculturales. (...) Pero, precisamente por esta razón, siempre estamos dentro de un sistema cultural y, en el interior de ese sistema, no podemos no tomar decisiones y hacer juicios. Quien se esfuerza en negar el sentido de estas decisiones ¿desde dónde habla? ¿Se sitúa fuera de la cultura para anunciar que es imposible estar fuera de la cultura? ¿Fuera de la historia para anunciar que es imposible estar fuera de la historia? (...) Las diferencias no se contemplan en silencio: se influyen, se confrontan, se desafían y a través de su encuentro se modifican y modifican también sus propios criterios de verdad. El relativismo cultural es una idiotez ahistórica que vuelve sorda la dialéctica viva de las culturas (...) El pensamiento humano no está hecho de jaulas culturales estáticas y separadas; es una mezcla perpetua, en todos los niveles, a cualquier escala; una confrontación perpetua con otros pensamientos y con ese exterior que llamamos 'realidad' 
(...) juzgar y decidir es lo mismo que pensar y vivir (...) La conciencia de la variabilidad histórica y cultural del juicio no nos dispensa de juzgar. Nos hace precisamente más inteligentes y más abiertos, y nos permite juzgar mejor aquello que debemos juzgar" (2018, 150-152). Lamentablemente, tanto la relativización total de los valores como la búsqueda de la restauración de un pensamiento absoluto que, en respuesta a la "pérdida de piso de la deriva relativista", no admita discusión, son posiciones vigentes que cobran cada vez más protagonismo en el escenario actual. Ninguna de estas posiciones extremas es capaz de ver que existe "una tercera vía": la de la confrontación, la discusión y la crítica (Rovelli 2018, 160).

La propuesta nietzscheana de la voluntad de poder apunta, precisamente, a esta "tercera vía" en tanto está orientada no solo a desenmascarar lecturas dualistas y metafísicas que conducen a trasmundos -llámense estos Dios, Verdad, Bien- sino a iniciar un trabajo de reconstrucción desde el hombre, como centro indiscutible. Este "giro antropológico" presenta, además, la particularidad, de partir del reconocimiento y valoración de la finitud y materialidad del hombre. De esta manera, el hombre que ocupa el centro de su ontología se encuentra desnudo, desprovisto de los velos que hasta el momento legitimaban su posición y sentido en el mundo. Considera Nietzsche que solo bajo un horizonte de estas características puede el hombre hacerse realmente cargo de sí mismo. Es por ello que la categoría de creación, más aún, la de creación de valores, adquiere, por primera vez, protagonismo ontológico, y el superhombre, en tanto promesa de futuro, es caracterizado como productor-creador del mundo-valor. Es entonces desde la comprensión de la voluntad de verdad articulada como voluntad de poder, y, en este sentido, como una voluntad que se ve a sí misma más como creadora que como descubridora, que Nietzsche sitúa al poder en la esencia misma de la vida. Se trata pues de una visión estética, que se libera de la metafísica de los valores supremos y que reconoce al sujeto fingidor de una hermandad igualadora (Sloterdijk 2000, 162). La moral del superhombre nietzscheano no puede, ni pretende, ser universalizable, más aún, desea ser superada. De esta manera, colisiona con la lógica de la conservación de todo instinto de rebaño. 


\section{Bibliografía}

Conill Sancho, Jesús, 2007. El poder de la mentira: Nietzsche y la política de la transvaloración. Madrid:Tecnos.

Danto, Arthur, 1980. Nietzsche as Philosopher. New York: Columbia University Press.

Fink, Eugen, 1989. La filosofía de Nietzsche. Madrid: Alianza Editorial.

Hanza, Kathia, 2001. “Espinas y secretos aromas. Pensamientos de Nietzsche sobre el perspectivismo en la historia". En: Nietzsche en perspectiva. Bogotá: Siglo del Hombre Editores, 181-197.

Müller-Lauter, Wolfgang, 1999. Nietzsche: His Philosophy of Contradictions and the Contradictions of his Philosophy. Traducción de David J. Parent. University of Illinois Press.

Nehamas, Alexander, 2002. Nietzsche, la vida como literatura. Madrid: Turner.

Nietzsche, Friedrich, 1999. Sobre la utilidad y el perjuicio de la historia para la vida. Madrid: Biblioteca Nueva.

- 2001. La gaya ciencia. Madrid: Colección Austral.

- 2003. La filosofía en la época trágica de los griegos. Madrid: El Club de Diógenes.

- 2006. La genealogía de la moral. Madrid: Alianza Editorial.

- 2007. Humano demasiado humano. Madrid: Akal.

- 2009. Así habló Zaratustra. Madrid: Alianza Editorial.

- 2012. Más allá del bien y del mal. Madrid: Alianza Editorial.

- 2013. Crepúsculo de los ídolos. Madrid: Alianza Editorial.

— 2014a. "La gaya ciencia". En: Obras completas III. Obras de madurez I, ed. Diego Sánchez Meca. Madrid: Tecnos.

- 2014b. La voluntad de poder. Madrid: Edaf.

Perniola, Mario, 2002. El arte y su sombra. Madrid: Cátedra.

- 2006. Contra la comunicación. Buenos Aires: Amorrortu.

Rovelli, Carlo, 2018. El nacimiento del pensamiento científico: Anaximandro de Mileto. Barcelona: Herder.

Sloterdijk, Peter. 2000. El pensador en escena: el materialismo de Nietzsche. Valencia: Pre-Textos. 